\title{
Class Attendance System using Wi-Fi Direct
}

\author{
Lawrence Ephrim \\ University of Cape Coast \\ Department of Computer Science and Information Technology \\ Cape Coast, Ghana \\ Hamza Umar \\ University of Cape Coast \\ Department of Computer Science and Information Technology \\ Cape Coast, Ghana
}

\author{
Augustine Kofi Blewudzi \\ University of Cape Coast \\ Department of Computer Science and Information Technology \\ Cape Coast, Ghana \\ Charles Roland Haruna \\ University of Cape Coast \\ Department of Computer Science and Information Technology \\ Cape Coast, Ghana
}

\author{
Alexander Asante \\ University of Cape Coast \\ Network and Infrastructure Section \\ Cape Coast, Ghana
}

\begin{abstract}
Recording class attendance has been a long-standing problem in academia. Manual attendance recording wastes lots of teaching time and is therefore considered inefficient. This paper presents an automated attendance recording system that solves the problem by utilizing Wi-Fi Direct, a feature that is available on smartphones owned by all students. This solution uses a combination of Wi-Fi Direct and network sockets for the class broadcasting and verification process. In this system, students get their attendance recorded by broadcasting their details via Wi-Fi Direct. The teacher's device listens and records new broadcasts which match the course. When a device is found, a socket connection is established and the students are notified that their attendances have been recorded. This solution helps teachers concentrate on teaching instead of wasting time on classroom attendance recording.
\end{abstract}

\section{Keywords}

Attendance System, Wi-fi Direct, Network Sockets

\section{INTRODUCTION}

Students' class attendance is a strong indicator of academic success. According to [13], a meta-analysis of the relationship between class attendance in college and college grades reveals that attendance has strong relationships with both class grades and Grade Point Average (GPA). The class attendance recording process is usually carried out by students appending their signatures on an attendance sheet provided by the lecturer or teaching assistant during or at the end of a class. In some instances, the attendance sheet is carried around in the lecture hall for each student to sign. At the end of the class, the lecturer or teaching assistant enters the records onto a system, usually an excel sheet, to keep track of recorded class attendances.

[15] estimated that a class of 30 students will require 15 minutes to complete the attendance recording process, assuming each student takes 30 seconds to fill the sheet. This laborious process combined with entering the recorded data into a system, usually an excel sheet, make many teachers give up on checking students' class attendance although many students fail to attend class. The need for an automated class attendance system cannot, therefore, be disputed and overlooked. This system will ease the workload on lecturers required to record class attendance.

\section{LITERATURE REVIEW}

Many automated attendance recording systems have been proposed to solve this problem. These solutions include facial recognition, Radio Frequency Identification (RFID) technology tags, QR codes, the use of Bluetooth beacons, Wi-fi Hotspot, among many others.

[3] Classified automated attendance systems into two categories based on their verification process; biometric-based and nonbiometric-based. Biometric-based attendance systems rely on human biological attributes which are unique per person as the identification(ID). The fingerprint is the most frequently used attribute for identification [9][10]. A hand-held device is used to mark the attendance without the intervention of the teacher. The device is passed around and students mark attendance during lecture time. Students place their fingers over the sensor to mark their presence in the class. Other biometric-based systems also rely on voice assistants and voiceprint [2][4]. The assistant receives a prompt from the teacher, authorizing the start of the process of attendance, this is then followed by the input from each attendee for the updating of the attendance database present on a server. 


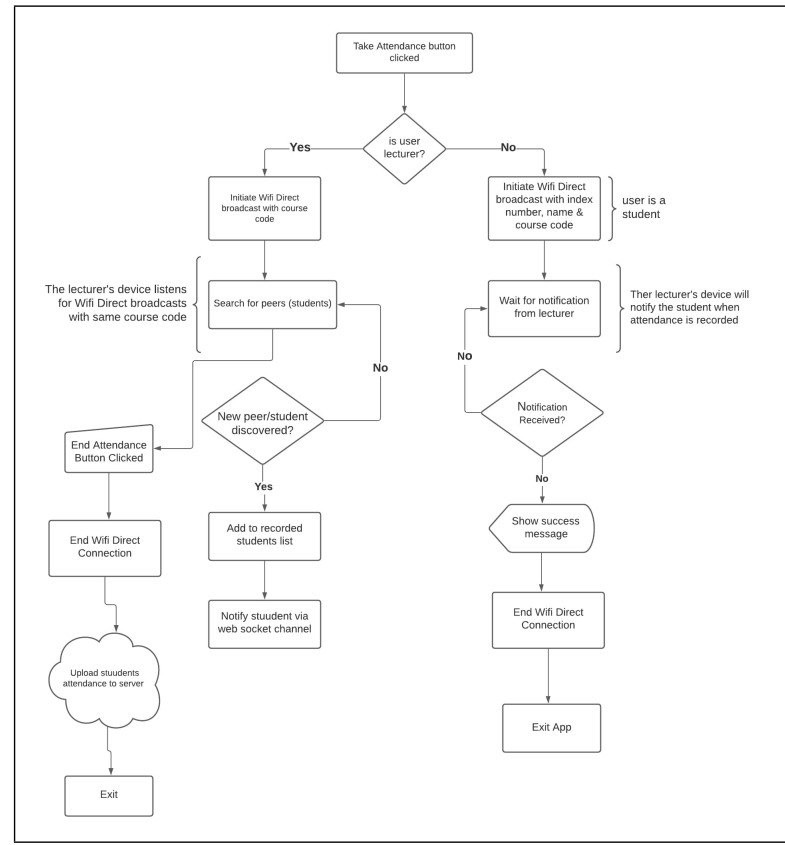

Fig. 1. Overview of Process Flow

A growing number of attendance systems use the human face as the ID. Some of these systems can automatically recognize the attendees by face [1][5][14]. Other systems ask the attendees to select their faces [11]. Non-biometric-based systems use media that facilitate user authentication, such as Radio Frequency Identification (RFID) tag, QR code, barcode, smartphone, access point, beacon. [6] uses the attendees' mobile devices to scan a particular barcode for recording the attendance. [8] developed a prototype system that relies on Near Field Communication (NFC) or RFID tag/card to record student attendance. [7] the study proposed a solution whereby a mobile device running the attendance system application is passed around among the participants, one by one. When the participant of the lecture gets the device, he or she searches for his/her ID and name on the device. A participant records his/her attendance by confirming either by taking a selfie or providing a signature. At the end of the lecture, the registration data is sent to a central server. [13] employ a BLE (Bluetooth Low Energy) beacon device to transmit a magic number necessary for proper registration within the classroom. "Compared to the counterpart, nonbiometric-based systems are arguably more practical as the attendees are not required to register their biological data before using the systems. They are also more secure as the biological data is credential and can be easily misused. But they are more prone to bogus attendance; the tokens can be illegally brought by unauthorized people" [3].

\section{SYSTEM DESIGN}

The proposed system is divided into two (2) modules namely the web server module and mobile application module. These modules are integrated together for the full functionality of the system, even though each module performs distinct functions. Figure 1 illustrates the general process flow of the system and how the modules interact with each other. During a lecture session, students will open the mobile application, select the particular course and click on record attendance. The application will broadcast the course code, student's index number and full name via Wi-fi Direct. The app then waits for verification from the teacher's device. Teachers will open the mobile application, select the particular course and click on record attendance. The mobile app will start listening for Wifi Direct broadcasts which contain the course code of the selected course. When a match is found, the student's attendance is saved to a database and also notifies their device that attendance has been recorded.

\section{SYSTEM IMPLEMENTATION}

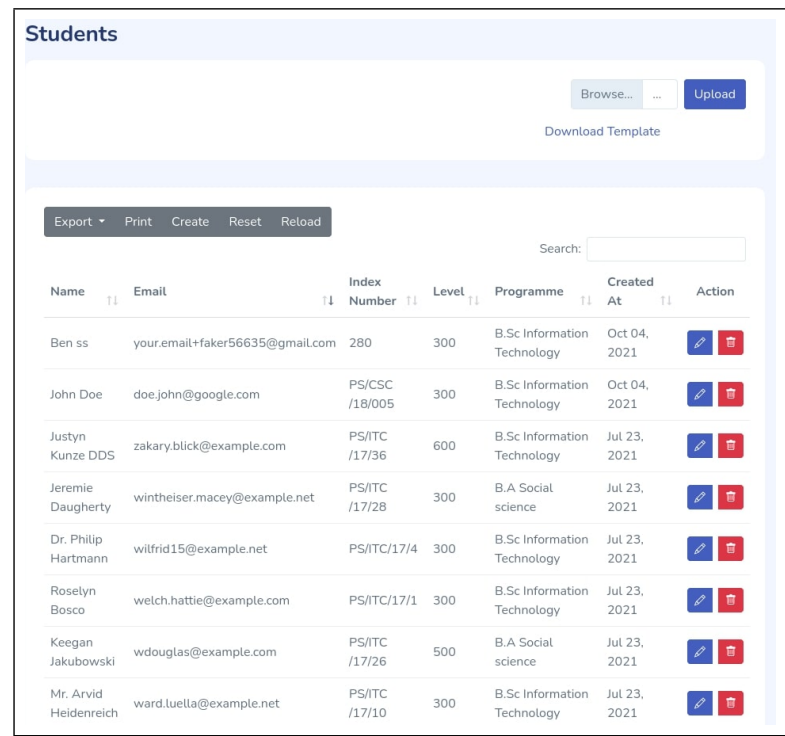

Fig. 2. Students List

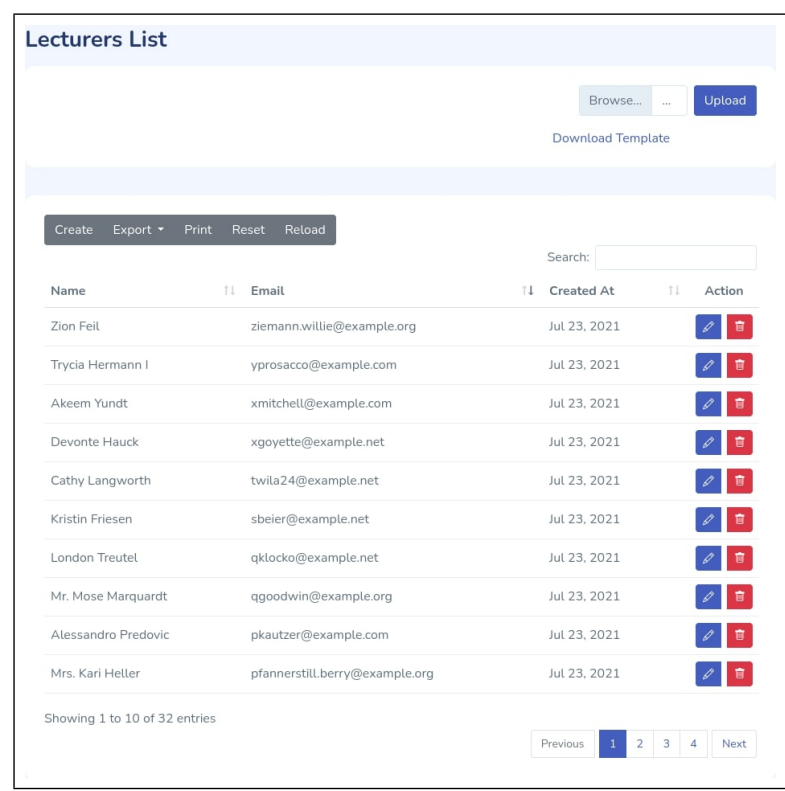

Fig. 3. Lecturers List 


\subsection{Students and Lecturers Registration}

As shown in Figure 2 and Figure 3 . both students and lecturers information is stored in a database that is managed using the web server module which is accessible to only the system administrator and lecturers. Only students and lecturers whose information is stored in the database can use the mobile application.

\subsection{Courses}

Similar to students information, all courses are stored in a database which is managed using the web dashboard module. Both lecturers and students are linked to a course(s). All attendances recorded for a particular course can be viewed on the courses page as shown in Figure 4 and Figure 5

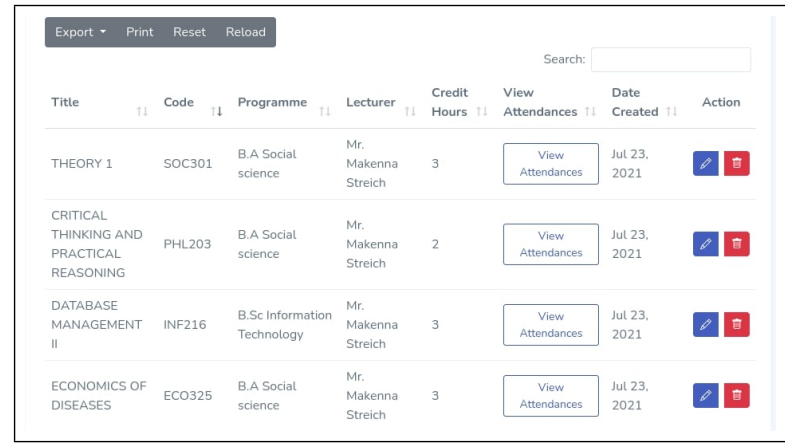

Fig. 4. Courses Page

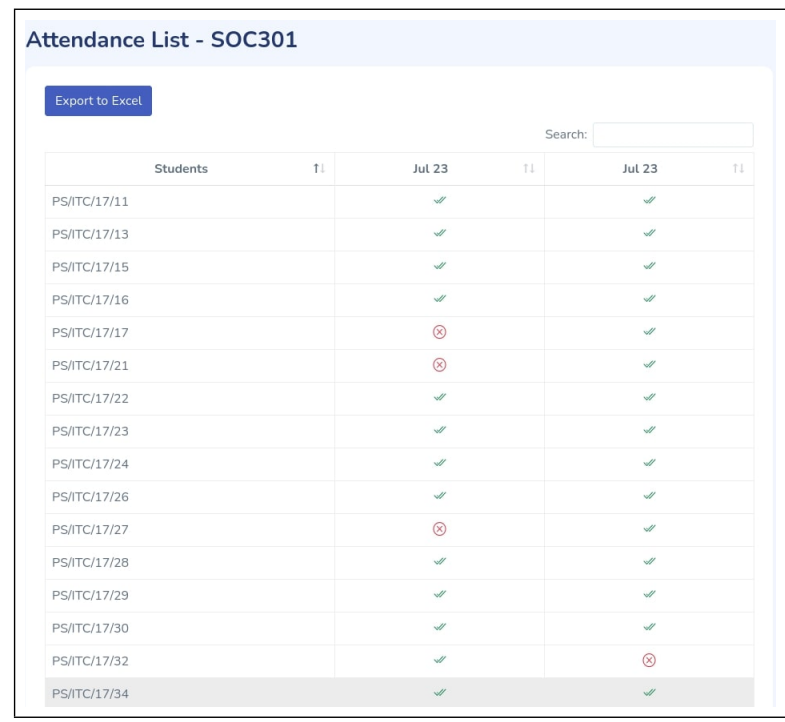

Fig. 5. Courses Attendances Page

\subsection{Mobile Application Login}

When the application is opened for the first time, the user is presented with a screen to choose the account type (either Lecturer or Student) as shown in Figure 6 Lecturers and instructors may log in using the Lecturer account type, which allows them to take class attendances. Lecturers can also view all the attendances and students for a particular course. As for the students, they must log in using the Student account type which allows them to record their attendance for a particular course.

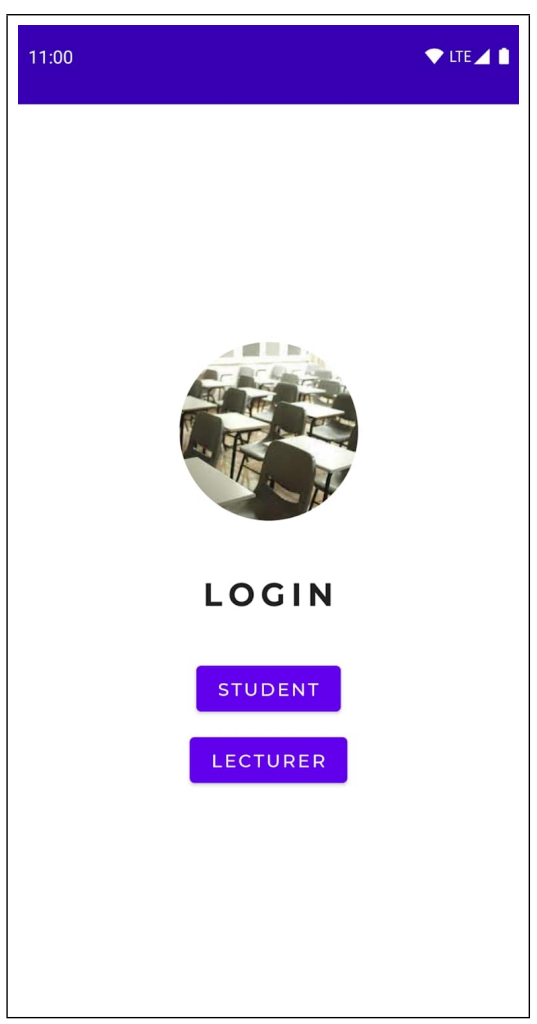

Fig. 6. Account Types Page

\subsection{Attendance Verification Process}

When the lecturer's device discovers a new device (student), the broadcasted information (full name, index number, course code), as well as the device's mac address, is tracked. Keeping track of these information ensures that each student can record attendance with and only one device. After successful verification, a notification is sent to the student's device via web socket that their attendance has been recorded as shown in Figure 8 After taking attendances, the lecturer will tap on the "END ATTENDANCE" button, Figure 7. which then uploads all the attendance information to the web server to be saved in a database.

\section{CONCLUSION}

This paper presents a method of attendance recording using Wi-Fi Direct which will make attendance taking during lectures as easy and less time consuming as possible, thus automating the entire process. The system will help lecturers to keep track of their student's attendance of the courses being taught. The class attendance system, like several alternative systems, could be created with more features and improved for higher quality to be up-to-date with current technologies. 


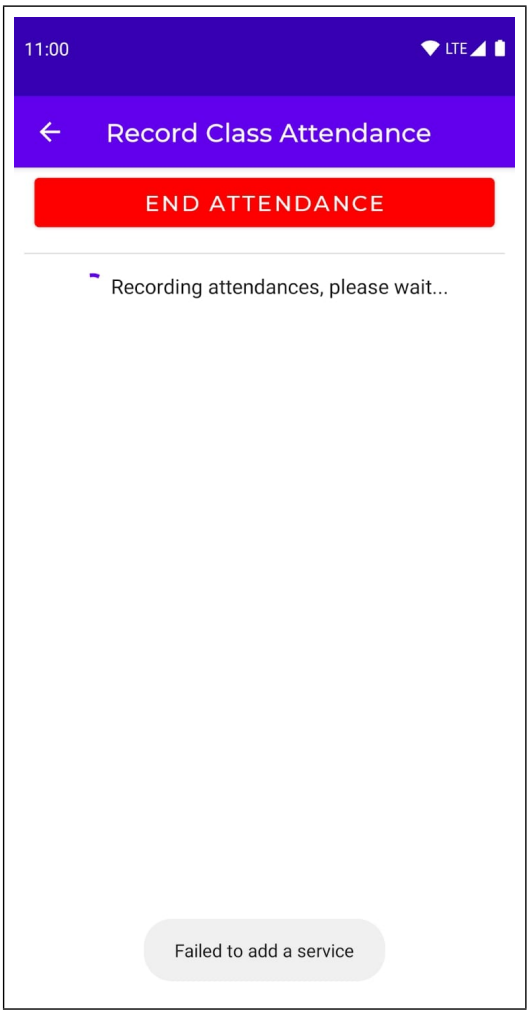

Fig. 7. Lecturer Attendance Recording Page

\section{REFERENCES}

[1] Okokpujie, K., Noma-Osaghae, E., John, S., Grace, K.A. and Okokpujie, I., 2017, November. A face recognition attendance system with GSM notification. In 2017 IEEE 3rd International Conference on Electro-Technology for National Development (NIGERCON) (pp. 239-244). IEEE.

[2] Byalpi, A.S., 2018, October. Alexa based Real-Time Attendance System. In 2018 3rd International Conference on Communication and Electronics Systems (ICCES) (pp. 121-124). IEEE.

[3] Panca, B.S., Paulus, Y. and Karnalim, O., 2020. An Automated Attendance System in Academia with Implicit Authentication via Mobile Devices and Wi-Fi Connection. International Journal of Online \& Biomedical Engineering, 16(7).

[4] Yang, S., Song, Y., Ren, H. and Huang, X., 2016, August. An automated student attendance tracking system based on voiceprint and location. In 2016 11th International Conference on Computer Science \& Education (ICCSE) (pp. 214219). IEEE.

[5] Rekha, E. and Ramaprasad, P., 2017, January. An efficient automated attendance management system based on Eigen Face recognition. In 2017 7th International Conference on Cloud Computing, Data Science \& Engineering-Confluence (pp. 605-608). IEEE.

[6] Noor, S.A.M., Zaini, N., Latip, M.F.A. and Hamzah, N., 2015, December. Android-based attendance management system. In 2015 IEEE Conference on Systems, Process and Control (ICSPC) (pp. 118-122). IEEE.

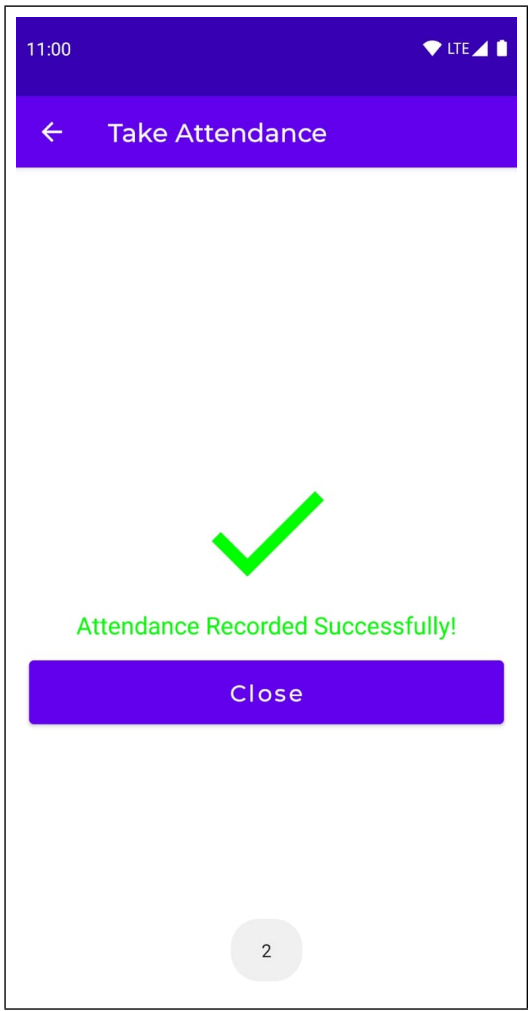

Fig. 8. Student Attendance Recorded Page

[7] Iio, J., 2016, September. Attendance management system using a mobile device and a web application. In 2016 19th International Conference on Network-Based Information Systems (NBiS) (pp. 510-515). IEEE.

[8] Mohandes, M.A., 2017. Class attendance management system using NFC mobile devices. Intelligent Automation \& Soft Computing, 23(2), pp.251-259.

[9] Mohamed, B.K. and Raghu, C.V., 2012, December. Fingerprint attendance system for classroom needs. In 2012 Annual IEEE India Conference (INDICON) (pp. 433-438). IEEE.

[10] Alhothaily, M., Alradaey, M., Oqbah, M. and El-Kustaban, A., 2015. Fingerprint attendance system for educational institutes. Journal of Science and Technology, 20(1).

[11] Budi, Setia, Oscar Karnalim, Erico D. Handoyo, Sulaeman Santoso, Hapnes Toba, Huyen Nguyen, and Vishv Malhotra. "IBAtS-Image based attendance system: A low cost solution to record student attendance in a classroom." In 2018 IEEE International Symposium on Multimedia (ISM), pp. 259-266. IEEE, 2018.

[12] Lukkarinen, A., Koivukangas, P. and Seppälä, T., 2016. Relationship between class attendance and student performance. Procedia-Social and Behavioral Sciences, 228, pp.341-347.

[13] Noguchi, S., Niibori, M., Zhou, E. and Kamada, M., 2015, September. Student attendance management system with bluetooth low energy beacon and android devices. In 2015 18th International Conference on Network-Based Information Systems (pp. 710-713). IEEE.

[14] Lukas, S., Mitra, A.R., Desanti, R.I. and Krisnadi, D., 2016, October. Student attendance system in classroom using face recognition technique. In 2016 International Conference on 
Information and Communication Technology Convergence (ICTC) (pp. 1032-1035). IEEE.

[15] Pambudi, D.S. and Bariyah, T., 2020. Student attendance system using wifi direct and temporary wi-fi hotspot. Jurnal Ilmu Komputer dan Informasi, 13(1), pp.1-8. 